\title{
Coliform Bacteria for Bioremediation of Waste Hydrocarbons
}

\author{
Majida Khanafer, Husain Al-Awadhi, and Samir Radwan \\ Microbiology Program, Department of Biological Sciences, Faculty of Science, Kuwait University, P.O. Box 5969, 13060 Safat, Kuwait
}

Correspondence should be addressed to Samir Radwan; samir.radwan@ku.edu.kw

Received 30 May 2017; Revised 26 July 2017; Accepted 6 August 2017; Published 10 September 2017

Academic Editor: Sardar Khan

Copyright (C) 2017 Majida Khanafer et al. This is an open access article distributed under the Creative Commons Attribution License, which permits unrestricted use, distribution, and reproduction in any medium, provided the original work is properly cited.

Raw, domestic sewage of Kuwait City contained about $10^{6} \mathrm{ml}^{-1}$ colony forming units of Enterobacter hormaechei subsp. oharae (56.6\%), Klebsiella spp. (36\%), and Escherichia coli (7.4\%), as characterized by their 16S rRNA-gene sequences. The isolated coliforms grew successfully on a mineral medium with crude oil vapor as a sole source of carbon and energy. Those strains also grew, albeit to different degrees, on individual $n$-alkanes with carbon chains between $\mathrm{C}_{9}$ and $\mathrm{C}_{36}$ and on the individual aromatic hydrocarbons, toluene, naphthalene, phenanthrene, and biphenyl as sole sources of carbon and energy. These results imply that coliforms, like other hydrocarbonoclastic microorganisms, oxidize hydrocarbons to the corresponding alcohols and then to aldehydes and fatty acids which are biodegraded by $\beta$-oxidation to acetyl CoA. The latter is a well-known key intermediate in cell material and energy production. E. coli cells grown in the presence of $n$-hexadecane (but not in its absence) exhibited typical intracellular hydrocarbon inclusions, as revealed by transmission electron microscopy. Raw sewage samples amended with crude oil, $n$-hexadecane, or phenanthrene lost these hydrocarbons gradually with time. Meanwhile, the numbers of total and individual coliforms, particularly Enterobacter, increased. It was concluded that coliform bacteria in domestic sewage, probably in other environmental materials too, are effective hydrocarbon-biodegrading microorganisms.

\section{Introduction}

Environmental pollution with spilled oil and waste hydrocarbons has become a problem of major concern on the global scale. Those compounds contaminate water and terrestrial and atmospheric ecosystems. Early reports estimated that about 0.08 to $0.4 \%$ of the internationally produced crude oil is spilled into the environment [1]. Probably this value has currently increased because of the ever increasing activities related to oil extraction from reservoirs, transportation, processing, use as an energy source, and accidents and military conflicts. Spilled oil may be removed using physiochemical or microbiological means. The former approach comprises the use of sorbents $[2,3]$, solidifiers $[4,5]$, dispersants $[6,7]$, and gelators $[8,9]$. However, the use of these products is not always environmentally safe and may even cause additional pollution $[1,10]$. Bioremediation is the alternative approach commonly accepted as the most cost-effective and ecofriendly biotechnology available. Two practices are suggested for bioremediation: bioaugmentation and biostimulation [11].
In the former approach, oil-contaminated areas are inoculated with cocktails of hydrocarbonoclastic microorganisms [12-14]. Biostimulation, on the other hand, depends on enhancing already existing microorganisms by adding nutrients [11], surfactants [12, 15], and other materials. In this context, the characteristic feature of hydrocarbonoclastic microorganisms lies in their ability to utilize hydrocarbons as sole sources of carbon and energy through the wellestablished metabolic pathways. They possess hydroxylases (also called oxygenases) which introduce oxygen atoms from molecular oxygen into the hydrocarbon substrate producing fatty alcohols. The latter are further oxidized via the aldehydes (or ketones) to the corresponding fatty acids. The latter are biodegraded into the key intermediate metabolite acetyl CoA.

In bioaugmentation, an important question regarding the choice of hydrocarbonoclastic microorganisms to be inoculated should be considered. Essential prerequisites are that those organisms should easily succeed in colonizing the new environment and in standing competition with the already existing inhabitants $[16,17]$. Therefore, the term 
"autochthonous bioaugmentation (ABA)" has been suggested recently for such a practice [18-20].

In the course of our work on bioremediation of desert and aquatic ecosystems that had been heavily polluted with oil during the greatest man-made oil spill at the end of the 1991 Gulf-war, we used to isolate hydrocarbonoclastic bacteria that according to their 16S rRNA-gene sequences were coliforms. Such bacteria belonged predominantly to the genera Enterobacter, Klebsiella, Escherichia, and others. The literature includes several reports by other investigators on hydrocarbon-degradation by such coliforms [21-23]. Even the hazardous simple and polyaromatic hydrocarbons were reported to be degraded by coliforms such as Klebsiella and Enterobacter [24-26]. Also diesel oil [27] and constituent hydrocarbons of crude oil [28-31] were found to be degraded by various coliforms. However, in many of those studies, the hydrocarbonoclastic potential was based solely on the ability of the strains to grow in mineral media with hydrocarbons as sole sources of carbon and energy. In some of those reports, the coliform taxa were just listed in tables including the identified hydrocarbonoclastic isolates, without further elaboration on criteria for considering them as hydrocarbon degraders.

Coliform bacteria belong to the family Enterobacteriaceae, which comprises facultative anaerobic bacteria naturally inhabiting digestive tracts of warm-blooded animals including man. Therefore, such microorganisms are continuously discharged with feces, and E. coli, for example, makes up about $10 \%$ of the domestic sewage microflora worldwide.

The major objective of this study was to investigate the hydrocarbonoclastic potential of coliforms from local domestic sewage samples. For this, microbiological, biochemical, and cytological techniques of analysis were integrated to obtain a more comprehensive evidence for the hydrocarbonoclastic potential of the obtained isolates. Should coliforms prove to be effective oil-biodegraders, domestic sewage would be a cost-effective, accessible source of microorganisms to be used in oil-bioremediation via bioaugmentation. Within this context, domestic sewage frequently receives waste hydrocarbons as constituents of disposed plant and animal wastes.

\section{Materials and Methods}

2.1. Counting and Characterization of Coliforms in Raw Sewage. Three local raw domestic sewage samples were collected from Al-Jahra station and used to count and isolate their indigenous coliforms. The conventional dilution-plating method was adopted, and the coliform-selective medium, Eosin Methylene Blue Agar (EMB) [32, 33], was used. The coliform colonies were counted, subcultured, and purified on the above selective medium. Individual coliforms were also counted after they had been differentiated according to their characteristic morphologies on this medium; Enterobacter colonies were pink with dark centers, Klebsiella colonies mucoid pink, and Escherichia coli colonies black with green metallic sheen The isolates were further characterized according to their potential for acid and gas production from lactose fermentation at $37^{\circ} \mathrm{C}$ and $44^{\circ} \mathrm{C}$, following established routine procedures. Representative strains were isolated, purified, and characterized by comparing the sequences of their $16 \mathrm{~S}$ rRNA-genes with sequences of type strains in the GenBank database. The method was essentially as follows: The total genomic DNA was extracted with PrepMan Ultra Sample Preparation Reagent (Applied Biosystems, USA) following the manufacturer's description. The $16 \mathrm{~S}$ rRNA-genes were amplified by polymerase chain reaction (PCR) using a Veriti Thermal Cycler (Applied Biosystems, USA) and a standard protocol with initial denaturation at $95^{\circ} \mathrm{C}$ for $5 \mathrm{~min}$ and 32 cycles of denaturation at $94^{\circ} \mathrm{C}$ for $1 \mathrm{~min}$, annealing at $55^{\circ} \mathrm{C}$ for $1 \mathrm{~min}$, and primer extension at $72^{\circ} \mathrm{C}$ for $1 \mathrm{~min}$. The mixture PCR contained puReTaq Ready-To-Go PCR Beads (Amersham Biosciences, UK), $25 \mathrm{ng}$ of DNA template, $1 \mu \mathrm{L}$ of each of the universal primer combinations GM5F ( $5^{\prime}$-CCTACGGGAGGCAGCAG-3 $\left.{ }^{\prime}\right)$ and 907R (5' CCGTCAATTCMTTTGAGTTT-3 ${ }^{\prime}$ ) [34]. The reaction volume was completed to $25 \mu \mathrm{L}$ with molecular water (Sigma, UK). Partial sequencing of the $16 \mathrm{~S}$ rRNA-genes was done using a BigDye version Terminator Kit (Applied Biosystems, USA). The mixture contained $20 \mathrm{ng}$ of the DNA template, $2 \mu \mathrm{l}$ of the BigDye version 3.1 terminator, $2 \mu \mathrm{l}$ of the $5 \mathrm{x}$ sequencing buffer, $1 \mu \mathrm{L}$ of either $907 \mathrm{R}$, or GM5F and the final volume was brought up to $10 \mu \mathrm{L}$ with molecular water. Labeling was completed in the Veriti Thermal Cycler (Applied Biosystems, USA) using one cycle of $96^{\circ} \mathrm{C}$ for 1 min then 25 cycles of $1 \mathrm{~min}$ at $96^{\circ} \mathrm{C}, 5 \mathrm{~s}$ at $50^{\circ} \mathrm{C}$, and $4 \mathrm{~min}$ at $60^{\circ} \mathrm{C}$. The pure template DNA samples were processed in a $3130 \mathrm{xl}$ genetic analyzer (Applied Biosystems, USA). Sequencing analysis version 5.2 software (Applied Biosystems, USA) was used to analyze the results. Sequences were subjected to basic local alignment search tool analysis with the National Center for Biotechnology Information (NCBI, Bethesda, MD, USA) GenBank database [35]. A phylogenetic tree was constructed using neighbor joining including bootstrap analysis using PAUP* v.4 [36]. Bootstrap proportions were used on 2000 replicates.

2.2. Hydrocarbon Utilization Potential of Coliforms. All the coliform strains were tested for their ability to grow on a mineral medium [37] with oil vapor as a sole source of carbon and energy. The mineral medium had the following composition $\left(\mathrm{gl}^{-1}\right): 5.0 \mathrm{NaNO}_{3}, 0.56 \mathrm{KH}_{2} \mathrm{PO}_{4}, 0.86 \mathrm{Na}_{2} \mathrm{HPO}_{4}, 0.17 \mathrm{~K}_{2} \mathrm{SO}_{4}$, $0.37 \mathrm{MgSO}_{4} \cdot 7 \mathrm{H}_{2} \mathrm{O}, 0.007 \mathrm{CaCl}_{2} \cdot \mathrm{H}_{2} \mathrm{O}$, and $25 \mathrm{mll}^{-1}$ of a trace element solution consisting of $\left(\mathrm{gl}^{-1}\right) 2.32 \mathrm{CuSO}_{4} \cdot 5 \mathrm{H}_{2} \mathrm{O}, 0.39$ $\mathrm{Na}_{2} \mathrm{MoO}_{4} \cdot 2 \mathrm{H}_{2} \mathrm{O}, 0.66 \mathrm{KI}, 1.0$ EDTA, $0.4 \mathrm{FeSO}_{4} \cdot 7 \mathrm{H}_{2} \mathrm{O}$, and $0.004 \mathrm{NiCl}_{2} \cdot 6 \mathrm{H}_{2} \mathrm{O}$. The $\mathrm{pH}$ was adjusted to 7 . Strains capable of growth on that medium were considered "presumptive" hydrocarbonoclastic.

To study the range of pure hydrocarbons that could be utilized by the individual strains, a common inoculum (loopful in $5 \mathrm{ml}$ sterile water) was prepared for each strain, and one-loopful aliquots were streaked on the solid mineral medium containing $0.5 \%$ of individual $n$-alkanes ranging in chain lengths between $\mathrm{C}_{9}-\mathrm{C}_{20}, \mathrm{C}_{23}-\mathrm{C}_{26}, \mathrm{C}_{28}, \mathrm{C}_{30}$, and $\mathrm{C}_{36}$. The aromatics toluene, naphthalene, phenanthrene, and biphenyl were also investigated. Cultures were incubated at $30^{\circ} \mathrm{C}$ for $15 \mathrm{~d}$ and examined for growth.

2.3. Hydrocarbon Consumption by Coliforms. The crude oil and pure-hydrocarbon consumption by individual isolates 
was measured quantitatively by gas liquid chromatography (GLC). Aliquots, $100 \mathrm{ml}$, of the mineral medium [37] in $250 \mathrm{ml}$ flasks were supplied with $0.3 \%(\mathrm{w} / \mathrm{v})$ crude oil or pure hydrocarbons. Each flask was inoculated with $1 \mathrm{ml}$ cell suspension (a loopful of $48 \mathrm{~h}$ biomass in $5 \mathrm{ml}$ sterile water). The cultures were sealed to avoid hydrocarbon losses by volatilization and incubated at $30^{\circ} \mathrm{C}$ on an electrical shaker, $200 \mathrm{rpm}$, for 2 weeks. Three parallel replicates were prepared throughout. The residual hydrocarbons were recovered with three successive $10 \mathrm{ml}$ portions of pentane. The combined extracts were completed to $35 \mathrm{ml}$ using pentane, and $1.0 \mu \mathrm{l}$ was analyzed by GLC. The percent loss of the peak areas based on the peak areas of the control samples (similarly prepared, but using previously autoclaved bacteria) was calculated as a quantitative measure of the oil-removal. For GLC, we used an Agilent 7890A GC (USA) system equipped with FID, a DB-5 capillary column (Agilent Technologies, USA), and He as a carrier gas. The oven temperature started at $50^{\circ} \mathrm{C}$ for $3 \mathrm{~min}$, then rising at $3^{\circ} \mathrm{C} / \mathrm{min}$ to $80^{\circ} \mathrm{C}$, then rising at $8^{\circ} \mathrm{C} / \mathrm{min}$ to $256^{\circ} \mathrm{C}$, then rising at $30^{\circ} \mathrm{C} / \mathrm{min}$ to $330^{\circ} \mathrm{C}$, and holding at this temperature for $11 \mathrm{~min}$.

2.4. Hydrocarbon-Uptake by Coliforms. In this experiment, two strains of E. coli, one from domestic sewage and the other from wheat straw [38], were investigated. Using transmission electron microscopy (TEM), we examined sections of cells previously grown in conventional nutrient broth and of cells grown in the mineral medium containing $0.3 \%$ hexadecane [37] for intracellular hydrocarbon inclusions. Biomass samples were fixed with $2.5 \%$ glutaraldehyde in sodium cacodylate buffer (0.1 M; pH 7.4) for $2 \mathrm{~h}$ [39]. The cells were washed in the same buffer, postfixed with $1.0 \% \mathrm{OsO}_{4}$ (at $4^{\circ} \mathrm{C}$ for $2 \mathrm{~h}$ ), and washed three times in the same buffer. Cells were centrifuged at $5,000 \times \mathrm{g}$ for $10 \mathrm{~min}$ and the pellet was mixed with an equal volume of $2.0 \%$ noble agar. The agar was spread on a slide, left to solidify, and cut into small cubes. The cubes were dehydrated in an ascending series (30, 50,70 , and $100 \%$ ) of acetone in water and rinsed twice in $100 \%$ propylene oxide. Finally, the samples were embedded in Epon resin. Ultrathin sections [40] were obtained using an ultramicrotome Leica (Leica Microsystems, Germany). The sections were mounted on carbon-coated grids, stained with saturated uranyl acetate and Reynolds lead citrate [41], and viewed in an electron microscope, JEM 1200-EX II (JEOL, USA).

2.5. Oil-Removal in Sewage Batches. Aliquots, $100 \mathrm{ml}$ of freshly harvested raw sewage (not previously sterilized) in $250 \mathrm{ml}$ flasks, were provided separately with 1.0 and $5.0 \mathrm{~g}$ portions of crude oil, $1.0 \mathrm{~g}$ portions of $n$-hexadecane, and $1.0 \mathrm{~g}$ portions of phenanthrene. The flasks were sealed to avoid hydrocarbon volatilization and incubated at $30^{\circ} \mathrm{C}$ on an electrical shaker, $200 \mathrm{rpm}$, for $20 \mathrm{~d}$. At time zero and in $5 \mathrm{~d}$ intervals, cultures were harvested for quantitative oil and coliform analysis, as already described. Three replicate samples were analyzed throughout.

A similar parallel experiment was run but using previously autoclaved raw sewage aliquots, as controls.
2.6. Statistical Analysis. Three determinations for each analysis were done and the mean values \pm standard deviation values were calculated using Microsoft Excel 2007. Also, Statistical Package for Social Sciences, version 12, was used to assess the degree of significance, where the analysis of variance (ANOVA) was used to differentiate between the means of the tested parameters.

\section{Results and Discussion}

3.1. Local Coliform Bacterial Strains. The three raw sewage samples studied were found to contain $9.5 \times 10^{5}, 9.8 \times$ $10^{5}$, and $9.6 \times 10^{5} \mathrm{ml}^{-1}$ colony forming units (CFU) of total coliform bacteria as counted on the selective coliform medium. Based on their 16S rRNA-gene sequences, those coliforms consisted of Enterobacter hormaechei subsp. oharae, 56-58\%; Klebsiella variicola, 23-25\%; Klebsiella pneumonia, 10-11\%; and Escherichia coli, $7-10 \%$. The results in Table 1 show that the sequence similarities between the isolates and the standard strains in the GenBank database were high, between 99 and 100\%. The phylogenetic relationships among the isolates are shown in the phylogenetic tree in Figure 1. The results of the conventional test for acid and gas production from lactose by the 4 coliform isolates (Table 2 and Figure S1 in the Supplementary Material available online at https://doi.org/10.1155/2017/1838072) were those expected according to their generic identities.

3.2. Oil and Hydrocarbon Utilization by the Coliform Isolates. A total of 313 pooled coliform colonies (on the selective EMB medium) were subcultured and purified. All the pure cultures grew on a solid mineral medium [37] with crude oil vapor as a sole source of carbon and energy. This result indicates that all the isolated coliforms presumably have potential for hydrocarbon utilization.

Five haphazardly selected strains for each coliform species were found to grow, albeit with different intensities, on the solid mineral medium [37] supplied with the individual $n$-alkanes, $\mathrm{C}_{9}-\mathrm{C}_{20}, \mathrm{C}_{23}-\mathrm{C}_{26}, \mathrm{C}_{28}, \mathrm{C}_{30}$, and $\mathrm{C}_{36}$, and the individual aromatic hydrocarbons, toluene, naphthalene, phenanthrene, and biphenyl. The growth on such a wide range of aliphatic and aromatic hydrocarbons reflects a high potential for hydrocarbon utilization. Earlier investigators also found that the same coliform species isolated elsewhere could grow on oil and hydrocarbons as sole sources of carbon and energy [21-23]. Successful growth of all tested coliforms on aliphatic and aromatic hydrocarbons suggests that they, like all hydrocarbonoclastic microorganisms, produce monooxygenases and dioxygenases (hydroxylases), respectively [42-44]. Moreover, the further metabolic pathways in such coliforms are apparently similar to those in other hydrocarbonoclastic microorganisms. The fatty alcohols are oxidized to aldehydes (ketones) and ultimately to fatty acids, which in turn are degraded by $\beta$-oxidation to acetyl CoA units. The latter could then be used for synthesis of cell material and for the production of ATP through the tricarboxylic acid cycle.

The results in Table 3 show that representatives of the local coliform isolates removed quantitatively significant 


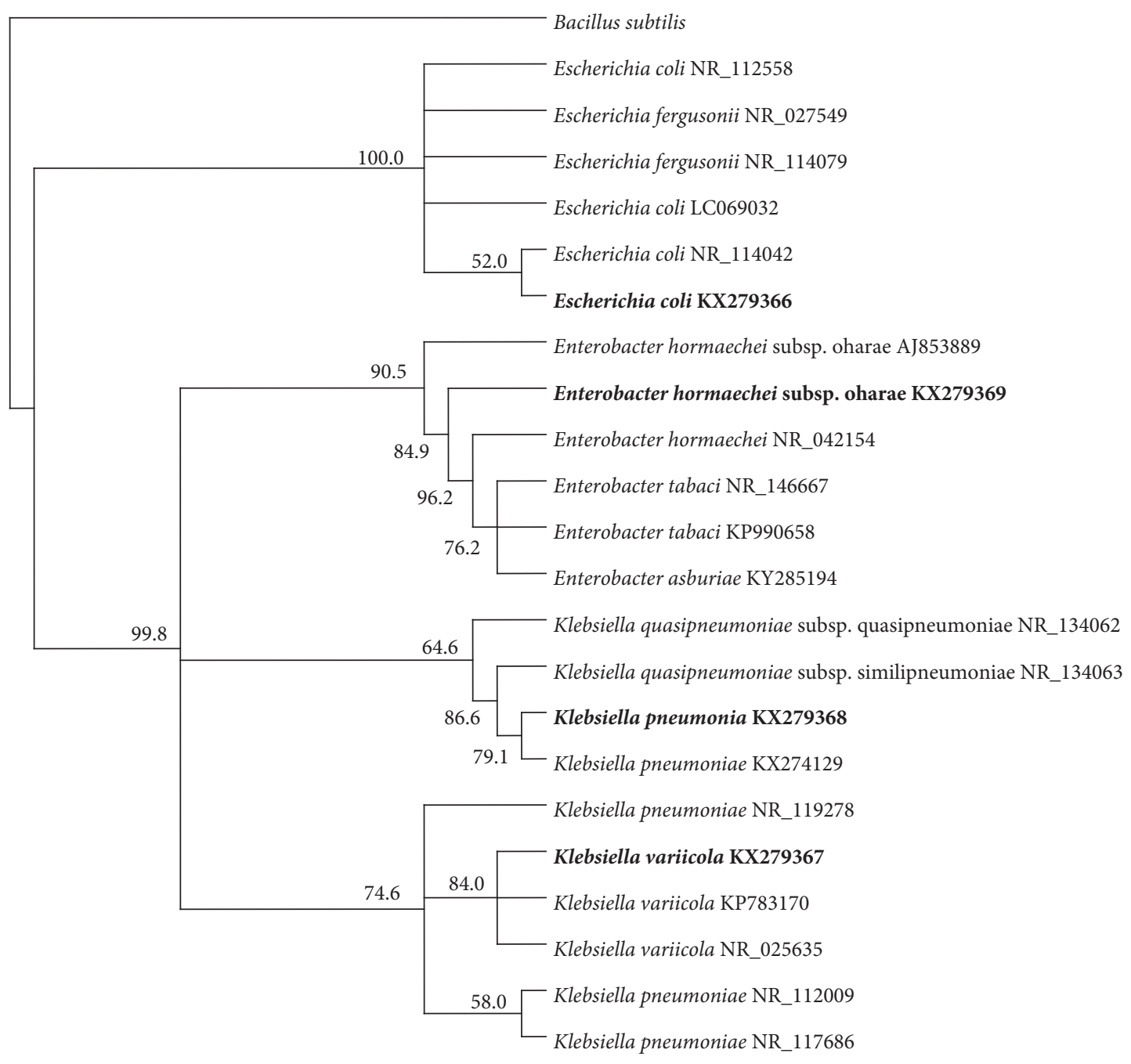

FIGURE 1: Phylogenetic tree showing relationships among coliforms isolated from domestic sewage.

TABLE 1: Information about the $16 \mathrm{~S}$ rDNA sequencing of the coliforms isolated from domestic sewage.

\begin{tabular}{lcccc}
\hline Nearest GenBank match & Total bases & Similarity (\%) & Compared bases & Accession number \\
\hline Escherichia coli & 513 & 100 & $513 / 513$ & KX279366 \\
Klebsiella variicola & 482 & 99 & $484 / 485$ & KX279367 \\
Klebsiella pneumoniae & 507 & 100 & $507 / 507$ & KX279368 \\
Enterobacter hormaechei subsp. oharae & 506 & 99 & $511 / 514$ & KX279369 \\
\hline
\end{tabular}

TABLE 2: Acid and gas production from lactose by coliform isolates.

\begin{tabular}{lcccc}
\hline Isolates & \multicolumn{2}{c}{ Acid production } & & Gas production \\
& $37^{\circ} \mathrm{C}$ & $44^{\circ} \mathrm{C}$ & $37^{\circ} \mathrm{C}$ & + \\
\hline Escherichia coli (wheat straw) & + & + & + & + \\
Escherichia coli (domestic sewage) & + & + & + & + \\
Klebsiella variicola & + & + & + & + \\
Klebsiella pneumoniae & + & + & + \\
Enterobacter hormaechei subsp. oharae & + & + & - \\
\hline
\end{tabular}


TABLE 3: Crude oil and pure-hydrocarbon consumption by coliform isolates.

\begin{tabular}{lccc}
\hline Isolates & & \% hydrocarbon consumption & C16 \\
Escherichia coli (wheat straw) & Crude oil & $17.1 \pm 1.0$ & $16.3 \pm 0.9$ \\
Escherichia coli (domestic sewage) & $18.3 \pm 1.1$ & $19.0 \pm 2.2$ & $18.1 \pm 3.0$ \\
Klebsiella variicola & $22.2 \pm 3.2$ & $12.3 \pm 0.8$ & $11.0 \pm 0.5$ \\
Klebsiella pneumoniae & $16.6 \pm 1.0$ & $10.6 \pm 0.8$ & $10.9 \pm 1.0$ \\
Enterobacter hormaechei subsp. oharae & $14.2 \pm 1.2$ & $35.9 \pm 2.0$ & $18.5 \pm 0.8$ \\
Pseudomonas stutzeri & $30.3 \pm 1.5$ & $18.4 \pm 0.8$ & $14.1 \pm 0.7$ \\
\hline
\end{tabular}

Pseudomonas stutzeri from our private culture collection was analyzed as a classic hydrocarbon-utilizer for the purpose of comparison.

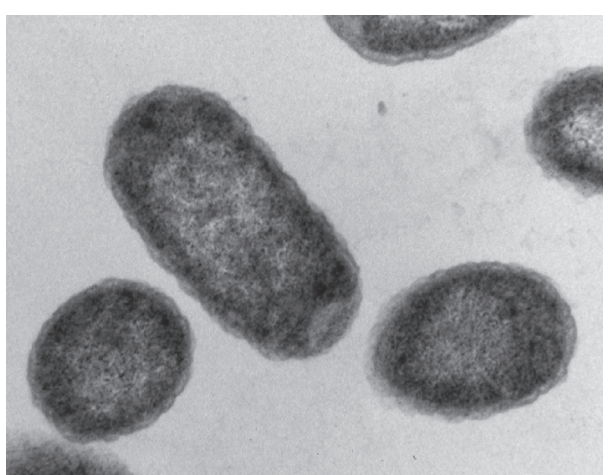

(a)

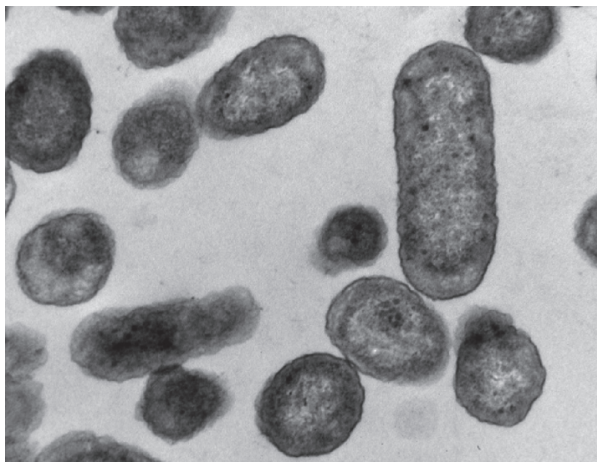

(c)

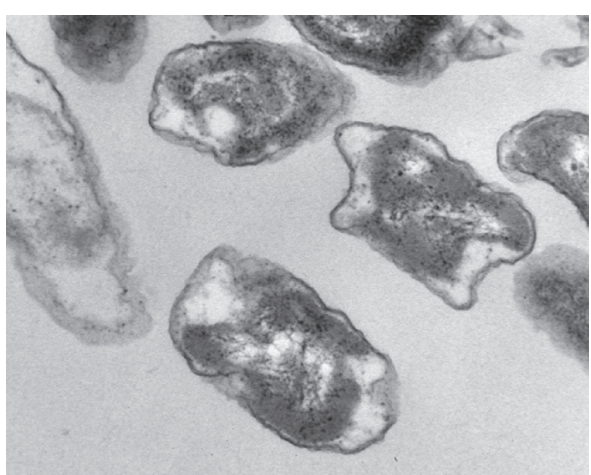

(b)

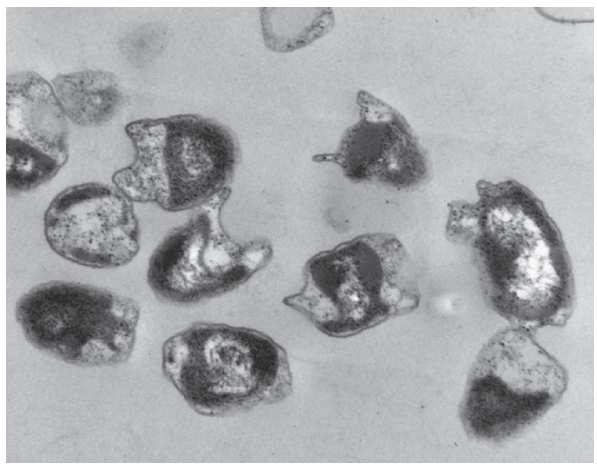

(d)

FIGURE 2: Transmission electron micrographs of ultrathin sections of $E$. coli cells from domestic sewage grown in $n$-hexadecane-free medium (a) and in $n$-hexadecane-containing medium (b) and of E. coli cells from wheat straw grown in $n$-hexadecane-free medium (c) and in $n$ hexadecane-containing medium (d). Magnification: (a) and (b) $\times 60000$; (c) and (d) $\times 40000$.

proportions of the available crude oil as well as of the pure aliphatic $\left(\mathrm{C}_{16}\right)$ and aromatic (phenanthrene) hydrocarbons in 15 days. Those hydrocarbons were provided in the mineral medium [37] as sole sources of carbon and energy. These quantitative determinations provide a clear-cut evidence for the hydrocarbonoclastic potential of the studied coliforms.

3.3. Cytological Evidence for $n$-Hexadecane $\left(C_{16}\right)$ Uptake by $E$. coli. For this experiment, two strains of the typical coliform, E. coli, one from sewage and the other from wheat straw [38], were used. The TEM images in Figure 2 show that the cell cytoplasm of hydrocarbon-incubated cells, in contrast to that of cells harvested from nutrient broth (without hydrocarbons), was enriched with less electron-dense areas (hydrocarbon inclusions) of varying dimensions. Our measurements showed that those inclusions occupied roughly $50 \%$ of the total cell volumes. Earlier researchers also described similar intracytoplasmic hydrocarbon inclusions in classical hydrocarbonoclastic bacteria incubated in media containing $n$-hexadecane [37]. Cells incubated in the presence of $\mathrm{C}_{16}$ also showed clear morphological deformations.

3.4. Self-Cleaning of Oily Sewage by Indigenous Coliforms. The results in Figure 3 show that crude oil, C18, and phenanthrene added to freshly harvested raw sewage (not previously sterilized) were steadily removed during the $20 \mathrm{~d}$ incubation period. At the end, the remaining proportions were only $70 \%$ of $3 \%$ crude oil, $45 \%$ of $1 \%$ crude oil, $66 \%$ of $\mathrm{C} 18$, and $55 \%$ 

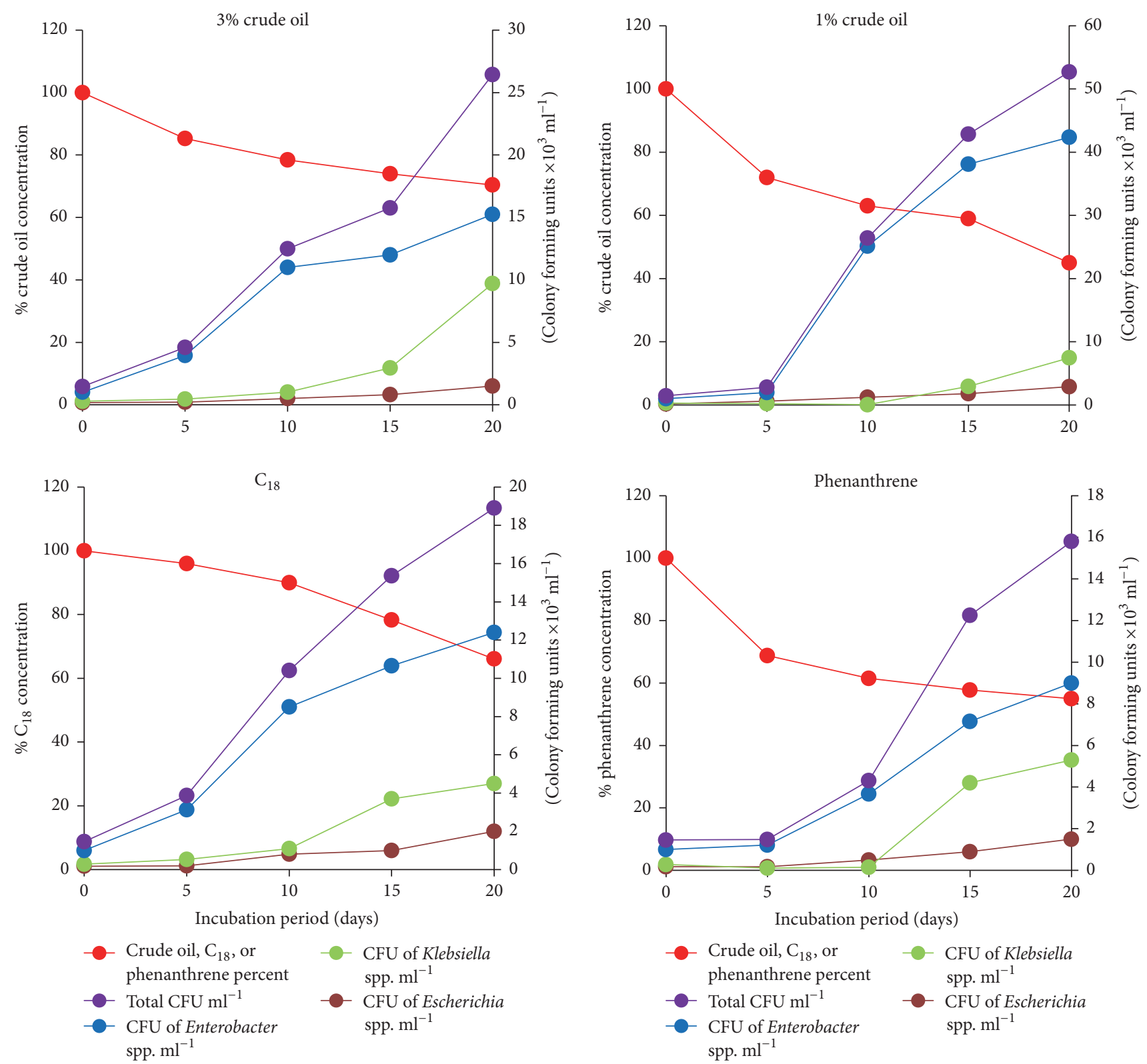

Figure 3: Consumption of crude oil added to freshly harvested sewage and parallel increase of total coliform members with time.

of phenanthrene, based on the amount added at time zero. Meanwhile, there was a parallel increase of the total numbers of the total coliforms from $1.46 \times 10^{6}$ to $26.5 \times 10^{6} \mathrm{CFU} \mathrm{ml}^{-1}$ in $3 \%$ crude oil, to $52.7 \times 10^{6} \mathrm{CFU} \mathrm{m}^{-1}$ in $1 \%$ crude oil, to $18.9 \times 10^{6} \mathrm{CFU} \mathrm{ml}^{-1}$ in $\mathrm{C} 18$, and to $15.8 \times 10^{6} \mathrm{CFU} \mathrm{ml}^{-1}$ in phenanthrene. Figure 3 shows further that Enterobacter was the coliform that exhibited the highest increase in number, which may reflect a main role of this coliform in oil consumption. Other hydrocarbonoclastic, noncoliform bacteria indigenous to sewage are also probably involved in the measured crude oil removal. However, the significant increase $(p<0.05)$ in numbers of coliforms parallel to the significant decrease $(p<0.05)$ in the concentration of the remaining oil provides an experimental evidence for a major contribution of indigenous coliforms to self-cleaning of oil in sewage. This finding implies that the indigenous domestic sewage microflora is capable of controlling potential oil spills in this waste product. Furthermore, raw sewage is an accessible, cost-effective source of hydrocarbonoclastic microbial cocktails that can be used for bioaugmenting oil-contaminated areas.

\section{Conclusions}

The results of this paper provide experimental evidence for the role of coliforms in biodegradation of oil spilled in the environment. This group should be particularly effective in cleaning oil spills in sewage, where those organisms are autochthonous (indigenous). Conditions prevailing during conventional sewage treatment probably bioenhance the 
coliforms potential for oil-bioremediation. On one hand, sewage treatment involves the routine practice of extensive aeration to reduce the sewage BOD values (i.e., the organic matter content). In view of the fact that the initial step of microbial attack on hydrocarbons is catalyzed by oxygenases (also called hydroxylases), aeration should bioenhance the spilled-oil bioremediation. Oil-bioremediation is also bioenhanced by nitrogen-fertilizers. During sewage treatment, nitrates and other nitrogenous compounds are continuously produced and in addition several coliforms, for example, Klebsiella spp. and Enterobacter spp., are diazotrophic. In other words, nitrogen fertilization is also guaranteed in sewage for the hydrocarbonoclastic coliform communities.

\section{Conflicts of Interest}

The authors declare that there are no conflicts of interest regarding the publication of this paper.

\section{Acknowledgments}

This work has been supported by Kuwait University, Research Grant SL06/16. Thanks are due to SAF Analysis Facility for providing Genetic Analysis through Project GS01/02, to NUERS for providing GLC analysis through Project SRUL01/ 13, and to the Nanoscopy Science Center for the technical assistance with transmission electron microscopy.

\section{References}

[1] National Research Council (NRC), Using Oil Spill Dispersants on the Sea, National Academy Press, Washington DC, Wash, USA, 1989.

[2] A. A. Al-Majed, A. R. Adebayo, and M. E. Hossain, "A sustainable approach to controlling oil spills," Journal of Environmental Management, vol. 113, pp. 213-227, 2012.

[3] A. Bayat, S. F. Aghamiri, A. Moheb, and G. R. Vakili-Nezhaad, "Oil spill cleanup from sea water by sorbent materials," Chemical Engineering and Technology, vol. 28, no. 12, pp. 1525-1528, 2005.

[4] D. Sundaravadivelu, M. T. Suidan, A. D. Venosa, and P. I. Rosales, "Characterization of solidifiers used for oil spill remediation," Chemosphere, vol. 144, pp. 1490-1497, 2016.

[5] W. Dahl, R. R. Lessard, E. Cardello et al., "Solidifiers for oil spill response," in Proceedings of the SPE Health, Safety and Environment in Oil and Gas Exploration and Production Conference, pp. 803-810, New Orleans, LA, USA, 1996.

[6] L. Graham, C. Hale, E. Maung-Douglass et al., "Oil spill science: Chemical dispersants and their role in oil spill response," MASGP-15-015, 2016.

[7] A. Zolfaghari-Baghbaderani, M. Emtyazjoo, P. Poursafa et al., "Effects of three types of oil dispersants on biodegradation of dispersed crude oil in water surrounding two Persian Gulf provinces," Journal of Environmental and Public Health, vol. 2012, Article ID 981365, 8 pages, 2012.

[8] C. Ren, G. H. B. Ng, H. Wu et al., "Instant room-temperature gelation of crude oil by chiral organogelators," Chemistry of Materials, vol. 28, no. 11, pp. 4001-4008, 2016.

[9] J. Bachl, S. Oehm, J. Mayr, C. Cativiela, J. J. Marrero-Tellado, and D. D. Díaz, "Supramolecular phase-selective gelation by peptides bearing side-chain azobenzenes: effect of ultrasound and potential for dye removal and oil spill remediation,"
International Journal of Molecular Sciences, vol. 16, no. 5, pp. 11766-11784, 2015.

[10] E. E. Cordes, D. O. Jones, T. A. Schlacher et al., "Environmental impacts of the deep-water oil and gas industry: a review to guide management strategies," Frontiers in Environmental Science, vol. 4, 2016.

[11] R. M. Atlas and R. Bartha, Microbial Ecology: Fundamentals and Applications, vol. 70, Benjamin/Cummings Publishing Company Inc, 4th edition, 1998.

[12] A. Szulc, D. Ambrozewicz, M. Sydow et al., "The influence of bioaugmentation and biosurfactant addition on bioremediation efficiency of diesel-oil contaminated soil: feasibility during field studies," Journal of Environmental Management, vol. 132, pp. 121-128, 2014.

[13] I. Kuiper, E. L. Lagendijk, G. V. Bloemberg, and B. J. J. Lugtenberg, "Rhizoremediation: a beneficial plant-microbe interaction," Molecular Plant-Microbe Interactions, vol. 17, no. 1, pp. 615,2004

[14] H. Van Limbergen, E. M. Top, and W. Verstraete, "Bioaugmentation in activated sludge: current features add future perspectives," Applied Microbiology and Biotechnology, vol. 50, no. 1, pp. 16-23, 1998.

[15] Ł. Ławniczak, R. Marecik, and Ł. Chrzanowski, "Contributions of biosurfactants to natural or induced bioremediation," Applied Microbiology and Biotechnology, vol. 97, no. 6, pp. 2327-2339, 2013.

[16] S. S. Radwan, N. A. Sorkhoh, I. M. El-Nemr, and A. F. ElDesouky, "A feasibility study on seeding as a bioremediation practice for the oily Kuwaiti desert," Journal of Applied Microbiology, vol. 83, no. 3, pp. 353-358, 1997.

[17] S. S. Radwan, “Gulf oil spill,” Nature, vol. 350, no. 6318, pp. 456460, 1991.

[18] S. Di Gregorio, M. R. Castglione, A. Gentini, and R. Lorenzi, "Biostimulation of the autochthonous bacterial community and bioaugmentation of selected bacterial strains for the depletion of polycyclic aromatic hydrocarbons in a historically contaminated soil," Geophysical Research Abstracts, vol. 17, 2015, EGU2015-14690.

[19] M. Nikolopoulou, N. Pasadakis, and N. Kalogerakis, "Evaluation of autochthonous bioaugmentation and biostimulation during microcosm-simulated oil spills," Marine Pollution Bulletin, vol. 72, no. 1, pp. 165-173, 2013.

[20] A. Ueno, Y. Ito, I. Yumoto, and H. Okuyama, "Isolation and characterization of bacteria from soil contaminated with diesel oil and the possible use of these in autochthonous bioaugmentation," World Journal of Microbiology and Biotechnology, vol. 23, no. 12, pp. 1739-1745, 2007.

[21] S. K. Shekhar, J. Godheja, and D. R. Modi, "Hydrocarbon bioremediation efficiency by five indigenous bacterial strains isolated from contaminated soils," International Journal of Current Microbiology and Applied Sciences, vol. 4, no. 3, pp. 892-905, 2015.

[22] J. K. Nduka, L. N. Umeh, I. O. Okerulu et al., "Utilization of different microbes in bioremediation of hydrocarbon contaminated soils stimulated with inorganic and organic fertilizers," Journal of Petroleum \& Environmental Biotechnology, vol. 3, no. 2, p. 116, 2012.

[23] E. Díaz, A. Ferrández, M. A. Prieto, and J. L. García, "Biodegradation of aromatic compounds by Escherichia coli," Microbiology and Molecular Biology Reviews, vol. 65, no. 4, pp. 523-569, 2001. 
[24] G. Zafra, Á. E. Absalón, M. D. C. Cuevas, and D. V. CortésEspinosa, "Isolation and selection of a highly tolerant microbial consortium with potential for PAH biodegradation from heavy crude oil-contaminated soils," Water, Air, and Soil Pollution, vol. 225, no. 2, article 1826, 2014.

[25] S. E. Hassan, S. E. Desouky, A. Fouda, M. El-Gamal, and A. Alemam, "Biodegradation of phenanthrene by klebsiella sp isolated from organic contaminated sediment," Journal of Advances in Biology \& Biotechnology, vol. 4, no. 4, pp. 1-12, 2015.

[26] J. Godheja, S. K. Shekhar, and D. R. Modi, "Biodegradation of one ring hydrocarbons (benzene and toluene) and two ring hydrocarbons (acenapthene and napthalene) by bacterial isolates of hydrocarbon contaminated sites located in chhattisgarh: a preliminary study," Journal of Petroleum \& Environmental Biotechnology, vol. 6, no. 1, 2015.

[27] S. Ramasamy, A. Arumugam, and P. Chandran, "Optimization of Enterobacter cloacae (KU923381) for diesel oil degradation using response surface methodology (RSM)," Journal of Microbiology, vol. 55, no. 2, pp. 104-111, 2017.

[28] R. Akpe, A. O. Ekundayo, S. P Aigere et al., "Bacterial degradation of petroleum hydrocarbons in crude oil polluted soil amended with cassava peels," American Journal of Research Communication, vol. 3, pp. 99-118, 2015.

[29] L. U. Obi, H. I. Atagana, and R. A. Adeleke, "Isolation and characterisation of crude oil sludge degrading bacteria," SpringerPlus, vol. 5, no. 1, article 1946, 2016.

[30] F. A. Ikuesan, B. E. Boboye, and F. C. Adetuyi, "Comparative bioremediation of crude oil - contaminated soil samples using activated soil and activated cow dung," Sky Journal of Microbiology Research, vol. 4, pp. 021-030, 2016.

[31] G. Ghoreishi, A. Alemzadeh, M. Mojarrad, and M. Djavaheri, "Bioremediation capability and characterization of bacteria isolated from petroleum contaminated soils in Iran," Sustainable Environment Research, vol. 27, no. 4, pp. 195-202, 2017.

[32] D. J. Leininger, J. R. Roberson, and F. Elvinger, "Use of eosin methylene blue agar to differentiate Escherichia coli from other gram-negative mastitis pathogens," Journal of Veterinary Diagnostic Investigation, vol. 13, no. 3, pp. 273-275, 2001.

[33] M. Levine, "Differentiation of E. Coli and A. Aerogens on a simplified eosin-methylene blue agar," Journal of Infectious Diseases, vol. 23, no. 1, pp. 43-47, 1918.

[34] C. M. Santegoeds, T. G. Ferdelman, G. Muyzer, and D. De Beer, "Structural and functional dynamics of sulfate-reducing populations in bacterial biofilms," Applied and Environmental Microbiology, vol. 64, no. 10, pp. 3731-3739, 1998.

[35] S. F. Altschul, T. L. Madden, A. A. Schäffer et al., "Gapped BLAST and PSI-BLAST: a new generation of protein database search programs," Nucleic Acids Research, vol. 25, no. 17, pp. 3389-3402, 1997.

[36] D. L. Swafford, PAUP*: Phylogenetic Analysis Using Parasimany and Other Method, Version 4, USA; Sinauer Association, Sunderland, MA, USA, 1998.

[37] N. A. Sorkhoh, M. A. Ghannoum, A. S. Ibrahim, R. J. Stretton, and S. S. Radwan, "Crude oil and hydrocarbon-degrading strains of Rhodococcus rhodochrous isolated from soil and marine environments in Kuwait," Environmental Pollution, vol. 65, no. 1, pp. 1-17, 1990.

[38] N. Dashti, N. Ali, M. Khanafer, and S. S. Radwan, "Oil uptake by plant-based sorbents and its biodegradation by their naturally associated microorganisms," Environmental Pollution, vol. 227, pp. 468-475, 2017.
[39] I. Esteve, E. Montesinos, J. G. Mitchell, and R. Guerrero, "A quantitative ultrastructural study of Chromatium minus in the bacterial layer of Lake Cisó (Spain)," Archives of Microbiology, vol. 153, no. 4, pp. 316-323, 1990.

[40] E. Diestra, A. Solé, M. Martí, T. Garcia De Oteyza, J. O. Grimalt, and I. Esteve, "Characterization of an oil-degrading Microcoleus consortium by means of confocal scanning microscopy, scanning electron microscopy and transmission electron microscopy," Scanning, vol. 27, no. 4, pp. 176-180, 2005.

[41] E. S. Reynolds, "The use of lead citrate at high $\mathrm{pH}$ as an electron-opaque stain in electron microscopy," The Journal of Cell Biology, vol. 17, pp. 208-212, 1963.

[42] H. J. Rehm and I. Reiff, "Mechanisms and occurrence of microbial oxidation of long-chain alkanes," Advances in Biochemical Engineering, vol. 19, pp. 175-215, 1981.

[43] Ratledge, "Degradation of aliphatic hydrocarbons," in Developments in Biodeterioration of Hydrocarbons, I. Watkinson, Ed., vol. 1, pp. 1-44, Applied Science, Essex, 1978.

[44] S. S. Radwan and N. A. Sorkhoh, "Lipids of $n$-alkane-utilizing microorganisms and their application potential," Advances in Applied Microbiology, vol. 39, pp. 29-90, 1993. 

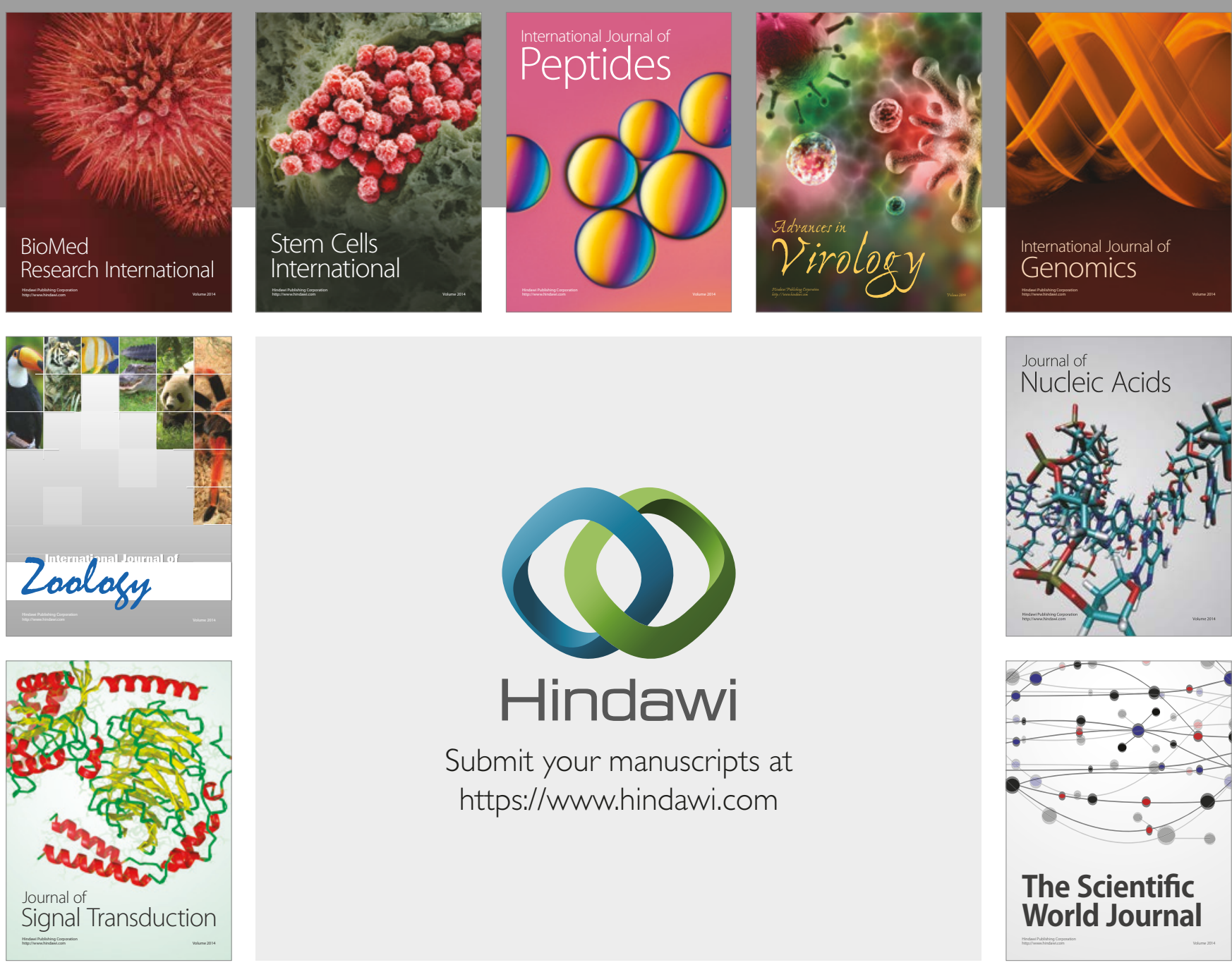

Submit your manuscripts at

https://www.hindawi.com
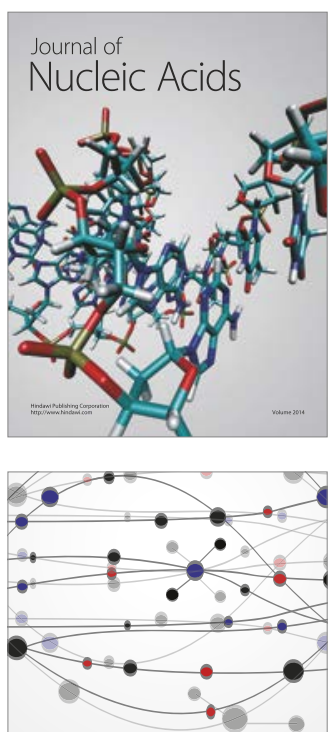

The Scientific World Journal

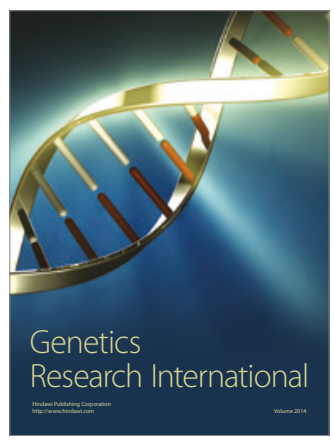

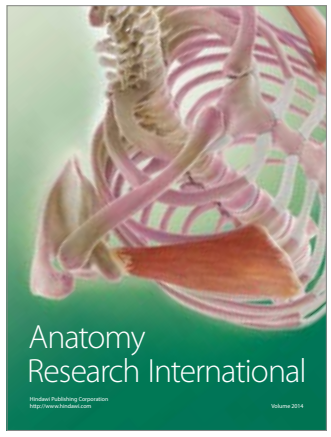

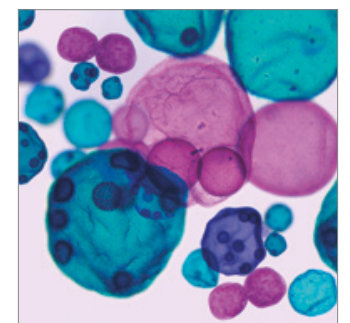

International Journal of Microbiology
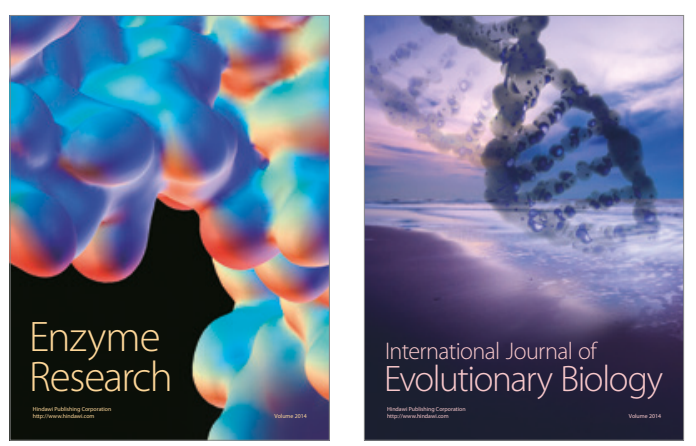
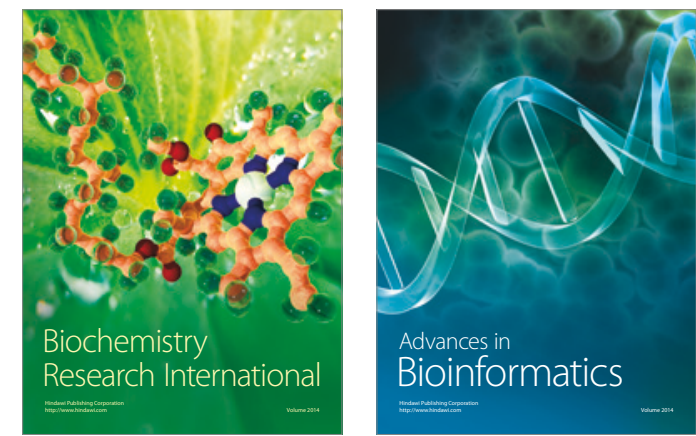

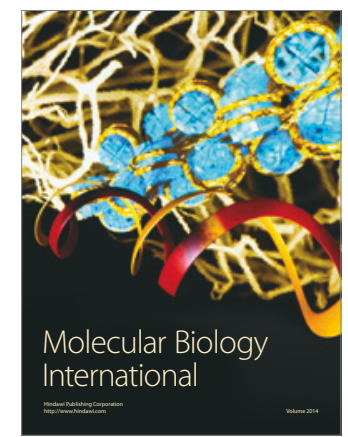

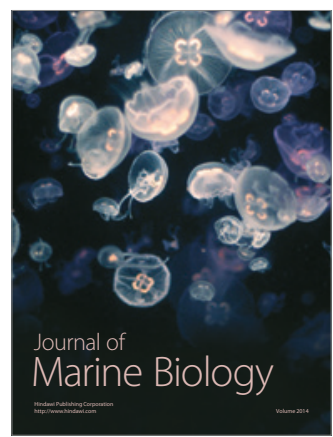

